style, with its triumphant announcement of his purchase of new premises for the Royal Society; number 878 , in which Newton announces the death of Colonel Robert Barton to his widow's father leaving the latter "discretion to let her know it by such degrees and in such manner as may least afflict her"; number 918, of interest for Newton's views on gravitational attraction; and number 961a, an important memorandum De Vi Electrica concerned with Newton's views on attractive forces. The volume is brought to a fitting close by Bentley's letter (1002) to Newton announcing the publication of the second edition of the Principia.

No review of this volume would be complete without a tribute to the late J. F. Scott, editor of volume 4, whose untimely death, following so closely on that of $\mathbf{H}$. W. Turnbull, was such a loss to this great project. It is to be hoped that the present editors will be able to carry it through to completion. Their editing of the present volume, including the footnotes and an admirable introduction, maintains the high standards set by preceding volumes. and makes it clear that no better choice of editors could be made for the project's final stages.

\section{Universal pictures}

The Amazing Universe. By Herbert Friedman. Pp. 200. (National Geographic Society: Washington, DC, 1975.) $\$ 4.25$.

The May 1974 issue of National Geographic included a feature on "The Incredible Universe"; this book develops the theme further with a new text by Herbert Friedman and a lavish use of colour illustrations. I am slightly disappointed, however, that the most has not been made of the opportunity to provide an account of the most intriguing theories of the new astronomy, and that the book largely rests on its illustrative laurels. Nevertheless, it is remarkably good value and helps to plug the gap between conventional 'popular' astronomy books and the revolutionary developments that have taken place in the past ten years or so.

Friedman has concentrated on discussion of the techniques of the new astronomy, which have opened up new parts of the spectrum and other areas to observation, but he does not complete the guided tour of theoretical work we have been led to expect. On solar neutrinos, for example, after describing the Davis experiment, we are merely told that "if the cleaning-fluid trap produces no neutrinos, the mystery . . . may force solar physicists to re-examine their theories"; the "mystery" of Sco X-1 is described as "a continuing challenge for today's Eddingtons", when in fact the source now seems to be well understood; Weber's gravitational radiation claims are to be "interpreted with extreme caution", when there is now a clear consensus which the author does not report; and the mention of apparent faster-than-light separations in some QSOs is followed by the vague comment that "some ingenious explanations for this have been put forward", when those explanations seem both straightforward and a clear indication of the illusory nature of the measured superlight speeds.

Even the professional astronomer may enjoy the pretty pictorial record, and as far as it goes The Amazing Universe is good value both in appearance and scientific content. It would make an ideal gift for a young reader freshly interested in astronomy, with the proviso that the donor should take care to follow this up with more meaty texts if the bait is taken.

John Gribbin

\section{"THE PETROLEUM GEOLOGY \\ Photochemistry} AND RESOURCES OF THE MIDDLE EAST"

by Professor Z. R. Beydoun and Dr. H. V. Dunnington

pp. vi +100 with 10 maps and diagrams Price £20 (UK only) or $\$ 50$ (other countries)

\section{"OILFFELDS OF THE WORLD"}

by Dr. E. N. Tiratsoo

\section{SECOND EDITION - JUST PUBLISHED}

pp. xvi +384 with 111 tables and many maps and diagrams, including a 4-colour section.

Price $£ 12.50$ (UK only) or $\$ 32$ (other countries)

\section{The Scientific Press Ltd.}

\author{
PO Box 21,
}

Beaconsfield, Bucks. HPg INS, England
Concepts of Inorganic Photochemistry. Edited by Arthur W. Adamson and Paul D. Fleischauer. Pp. ix +439. (Wiley Interscience: New York and London, August 1975.) £13.30.

THIS volume gives an account of the developments in coordination photochemistry, each chapter being contributed by an authority in the field. Two chapters deal with photophysical processes: the first is a brief survey of the electronic spectroscopy of complexes, the second an account of the kinetics of photophysical processes based on concepts well established in organic photochemistry. Against this background are set chapters on charge-transfer photochemistry, substitutional photochemistry of first-row transition elements, and on the photochemistry of the heavier elements, of carbonyl complexes, of 1,3-diketonate chelates and of simple inorganic ions in solution. In each of these chapters the existing experimental information on selected systems is critically reviewed and an attempt is made to interpret the data in terms of principles governing the reactivity of the excited state. The last two chapters are more speculative. The first deals with photochemistry in the solid state, a challenging field of great importance in which the difficulties of obtaining quantitative information and of interpreting it, are formidable. The brief final chapter on photochromism and chemiluminescence concentrates on general principles. It includes the novel suggestion that the "thermally equilibrated excited state" in photochemical reactions may be identified with a particular modification of the "transition state" postulated in thermal reactions.

These are stimulating reviews which give an excellent account of the present state of a rapidly developing subject. Overlap between chapters has been kept to a minimum; a degree of uniformity in terminology and treatment helps to emphasise the common factors in different areas of the subject. A minor source of irritation, however, is the inconsistency in the use of units-the variety of captions for wavelength and wave number, for example.

The book will be welcomed by investigators in the wide field of inorganic chemistry. With its emphasis on concepts and interpretation it should be of general interest to many inorganic chemists.

M. I. Christie 